Tropical Journal of Pharmaceutical Research June 2019; 18 (6): 1197-1204

ISSN: 1596-5996 (print); 1596-9827 (electronic)

(1) Pharmacotherapy Group, Faculty of Pharmacy, University of Benin, Benin City, 300001 Nigeria.

\title{
Effect of atractylenolide III on interstitial cells of Cajal and C-kit/SCF pathway of rats with loperamide-induced slow transit constipation
}

\author{
Wang Hao ${ }^{1}$, Gong Yuxia ${ }^{1}$, Li Youran ${ }^{1}$, Xu Minmin ${ }^{1}$, Gu Yunfei ${ }^{2 \star}$ \\ ${ }^{1}$ Department of Anorectal Surgery, Affiliated Hospital of Nanjing University of Chinese Medicine, ${ }^{2}$ Department of Anorectal \\ Surgery, Nanjing University of Chinese Medicine, Qinhuai District, Nanjing City, China
}

*For correspondence: Email: h75tdu@163.com

Sent for review: 21 February 2019

Revised accepted: 27 May 2019

\begin{abstract}
Purpose: To determine the effect of atractylenolide-III (ATL-III) on loperamide-induced slow transit constipation (STC) in a rat STC model, and to elucidate the mechanisms involved.

Methods: Male Wistar rats were divided into five groups ( $n=6$ per group): normal control group (NG), model group, and three STC rat groups treated with different doses of ATL-III, viz, 5, 10 and $15 \mathrm{mg} / \mathrm{kg}$. The rats were treated for 15 days. Feed consumption, fecal excretion and intestinal transit rate were determined. Nitric oxide synthase (NOS), somatostatin (SS), serotonin (5-HT), and vasoactive intestinal peptide (VIP) were measured with enzyme-linked immunosorbent assay (ELISA). The protein and mRNA expressions of C-kit, SCF, PKC, and PI-3K were assayed using Western blot analysis and realtime reverse transcription polymerase chain reaction (RT-PCR), respectively.

Results: The amount, weight, and moisture content of stool, and water consumption were significantly higher in ATL-III-treated groups than in the untreated (model) group $(p<0.05)$, whereas no difference was observed in feed intake. Intestinal transit rate was higher in the ATL-II--treated groups $(p<0.05)$. Decreased NOS, SS and VIP levels and increased 5-HT level were seen in the ATL-III-treated groups $(p<0.05)$. ATL-III treatment also induced increases in smooth muscle cells, neuronal cells, and mucous layer $(p<0.05)$. Results from RT-PCR and Western blot revealed that ATL-III-treated groups had elevated c-kit, SCF, PKC, as well as PI-3K mRNA and protein expressions $(p<0.05)$.

Conclusion: These results suggest that ATL-III mitigates loperamide-induced STC in rats via stimulation of NOS, SS, VIP, and 5-HT secretions. It also increases smooth muscle cells, neuronal cells, and mucous layer, and regulates the signaling pathways involving PKC, PI3K, SCF, and c-kit.
\end{abstract}

Keyword: Slow transit constipation, Atractylenolide III, Interstitial cells of Cajal, Smooth muscle cells, Neuronal cells, Mucous layer

This is an Open Access article that uses a fund-ing model which does not charge readers or their institutions for access and distributed under the terms of the Creative Commons Attribution License (http://creativecommons.org/licenses/by/4.0) and the Budapest Open Access Initiative (http://www.budapestopenaccessinitiative.org/read), which permit unrestricted use, distribution, and reproduction in any medium, provided the original work is properly credited.

Tropical Journal of Pharmaceutical Research is indexed by Science Citation Index (SciSearch), Scopus, International Pharmaceutical Abstract, Chemical Abstracts, Embase, Index Copernicus, EBSCO, African Index Medicus, JournalSeek, Journal Citation Reports/Science Edition, Directory of Open Access Journals (DOAJ), African Journal Online, Bioline International, Open-J-Gate and Pharmacy Abstracts

\section{INTRODUCTION}

Constipation is a global concern of public health, particularly affecting elderly population [1]. Slow transit constipation (STC) is caused by a disorder in colon transmission, and it is characterized by symptoms including infrequent and difficult defecation, accompanying with a sensation of 
incomplete bowel evacuation. The prevalence of STC in chronic constipation is about $46 \%$ [2]. The cure rate is low due to persistence of the clinical symptoms. Thus, the disease is often recrudesced, and may even induce colorectal tumors, prostatic hypertrophy and myocardial infarction.

Various chemical drugs such as cisapride, mosapride, and prucalopride are used for STC therapy, although their applications are restricted by high costs and various adverse effects [3]. Research in recent years have led to greater understanding of the pathogenesis of STC. In particular, studies on gastrointestinal nervous system, interstitial cells of Cajal (ICC) and proteomics have provided new perspectives for research on STC, as well as a scientific basis for research on new drugs for treatment of the disease. The interstitial cells of Cajal (ICC) are pacemaker cells which mediate neuromuscular transmission from nerve endings to smooth muscle cells, and regulate slow wave activity in the gastrointestinal tract $[4,5]$. It has been demonstrated that, in STC patients, the colonic ICC density is remarkably lower than in that in normal patients. Thus, restoration of ICC may be crucial in the cure for STC.

Using traditional Chinese herbal medicine formulas, scientists have opened new avenues in the treatment of chronic constipation in recent years [6,7]. According to the Chinese Pharmacopoeia, atractylodes is beneficial for spleen and stomach, and of clinical importance in the treatment of edema and diarrhea [8]. However, the effect of atractylodes on STC remains unclear. Atractylenolide III (ATL-III) has been reported as an important active constituent of atractylodes. It has good protective activity against corticosterone-induced damage to $\mathrm{PC} 12$ cells through a mechanism related to inhibition of neuronal apoptosis [9]. In addition, ATL-III prevents neuron loss and ameliorates cognitive impairment caused by chronic homocysteine (Hcy) administration in rats [10]. Thus, it can be speculated ATL-III may be the active principle involved in the treatment of STC with atractylodes. In this study, we aimed to determine the role of ATL-III on loperamide (Lop)-induced STC in rats, and the underlying mechanism.

\section{EXPERIMENTAL}

\section{Animals}

Thirty male Wistar rats $(150 \pm 30 \mathrm{~g})$ were purchased from Shanghai Laboratory Animal Research Center. All rats were maintained in standard cages with $12 \mathrm{~h} / 12 \mathrm{~h}$ light/dark cycle at room temperature and humidity. The access to food and drinking water were unlimited. This research was approved by the Animal Ethical Committee of Department of Anorectal Surgery, Nanjing University of Chinese Medicine, Qinhuai District, Nanjing City, China (approval no. 201713696), and performed according to $\mathrm{NIH}$ laboratory animal guidelines [11].

\section{Experimental design and treatment}

The thirty rats were divided into five experimental groups randomly ( $n=6$ per group): group $A$ : normal control group without any treatment (NG); group B: STC model group with mock treatment (Lop + vehicle-treated group); group C: STC group with low-dose ATL-III treatment (Lop + LDATL-III-treated group), group D: STC group with medium-dose ATL-III treatment (Lop + MDATL-III-treated group), and group E: STC group with high-dose ATL-III treatment (Lop + HDATL-III-treated group). Rats in group A were injected with physiological saline, while the others were treated with subcutaneous injection of Lop at the concentration of $4 \mathrm{mg} / \mathrm{kg}$ diluted in physiological saline. The injections were performed twice per day and lasted for 3 days. The doses of ATL-III were selected on the basis of previous studies [10-13]. Groups C, D, and E were treated with 5,10 , and $15 \mathrm{mg} / \mathrm{kg}$ ATL-III in water by oral administration, respectively. The oral administration was performed once a day from day 4 to day 18. Rats in groups $A$ and $B$ received equivalent volume of water in place of ATL-III via gavage.

\section{Assessment of water consumption and feed intake}

During the experimental period, alterations in water consumption and feed intake were observed and recorded every day. All measurements were performed in three independent experiments.

\section{Measurement of stool parameters}

The pellets excreted by each rat were collected at 10:00 am. The pellets were counted and stool weight was obtained three times per sample. Stool water content was calculated. All measurements were performed in three independent experiments.

\section{Assessment of intestinal transit time}

After 18 days treatment, all animals were subjected to $24 \mathrm{~h}$ fasting but with unlimited drinking water. Each rat was administered 0.5 
$\mathrm{mL}$ of ink, and a timer was immediately switched on. After $30 \mathrm{~min}$, all rats were sacrificed by abdominal injection of $200 \mathrm{mg} / \mathrm{kg}$ pentobarbital, and whole intestines from the rectum to the pylorus were taken out and straightened. Then, the entire length of the intestine and the distance the ink was propelled in the intestine were measured to calculate the intestinal transit rate, using Eq 1.

$\operatorname{ITR}(\%)=\mathrm{D} /(\mathrm{IL}]$

ITR: intestinal transit rate; $\mathrm{D}$ : distance traveled by the ink (in $\mathrm{cm}$ ); IL: intestinal length (in $\mathrm{cm}$ ). All measurements were performed in triplicate.

\section{Assessment of neurotransmitter levels in blood}

Before the rats were sacrificed, blood samples were obtained from their tail veins. Serum was obtained from blood samples by centrifugation at $3500 \mathrm{rpm}$ for $15 \mathrm{~min}$. The serum concentrations of nitric oxide synthase (NOS), somatostatin (SS), serotonin (5-HT), and vasoactive intestinal peptide (VIP) were measured with ELISA using commercially available kits. All measurements were performed in three independent experiments.

\section{Hematoxylin and eosin (H \& E) staining}

Colons were collected from control and experimental animals, and then fixed with $10 \%$ formalin for $12 \mathrm{~h}$, embedded in paraffin wax, followed by sectioning in $5 \mu \mathrm{m}$ thickness. Sections were then stained with hematoxylin and eosin (H \& E, Sigma-Aldrich, MO, USA). The images were acquired with Leica Application Suite (Leica Microsystems, Switzerland). All measurements were performed in three independent experiments.

\section{Immunohistochemistry assays}

Unstained sections were cut from the paraffin blocks which were prepared as described above. The sections were incubated for $1 \mathrm{~h}$ with PBST containing $5 \%$ BSA. Thereafter, they were incubated overnight at $4{ }^{\circ} \mathrm{C}$ with primary anti-c-kit (1:1000 dilution). Subsequently, the secondary antibody was used for $1 \mathrm{~h}$ at room temperature, followed by amplification with DAB Vectastain ABC kits (Vector Laboratories). The tissue sections were then examined under an upright Leica microscope, and the staining intensity was quantified using Image-Pro Plus 6.0 software (Mdia Cybernetics, Silver Springs, MD). All measurements were performed in triplicate.

\section{Western blotting}

Proteins from the transverse colon of all rats were subjected to $10 \%$ sodium dodecyl sulfatepolyacrylamide gel electrophoresis (SDS-PAGE) and transferred onto PVDF membranes. The membranes were blocked with $5 \%$ skim milk in $50 \mathrm{mM}$ Tris-buffered saline containing $0.1 \%$ Tween 20 (TBST), and were incubated separately with the primary antibodies anti-c-kit (\#37805, 1:1000 dilution); anti-SCF (\#2093, 1:1000 dilution); anti-PI3K (\#4249, 1:1000 dilution); anti-PKC (\#59754, 1:1000 dilution); Cell Signaling Technology Inc., Cambridge, MA, USA,), and anti-GAPDH (G9545, Sigma-Aldrich, Saint Louis, MO, USA, 1:2000 dilution) at $4^{\circ} \mathrm{C}$ overnight. Then the PVDF membranes were washed with TBST and incubated with horse radish peroxidase-conjugated secondary antibody [goat-anti-rabbit IgG (A32732, Zymed Laboratories, South San Francisco, CA, USA)] at a dilution of 1:5000, at room temperature for $1 \mathrm{~h}$. Finally, the signals were detected by ECL reagents, then images were acquired and analyzed by a Tanon image system. All measurements were performed in three independent experiments.

\section{Real-time reverse transcription polymerase chain reaction (Real-time RT-PCR)}

Total RNA was extracted from transverse sections of colon using TRIzol (Invitrogen, Grand Island, NA, USA), according to the manufacturer's instruction. The total RNA samples $(1-\mu \mathrm{g})$ were added to $12 \mu \mathrm{L}$ Oligo (dT) $(10 \mu \mathrm{M})$, and made up to a volume of $20 \mu \mathrm{L}$ with appropriate amount of water. The samples were heated at $70{ }^{\circ} \mathrm{C}$ for $10 \mathrm{~min}$ and then chilled on ice, and then reverse-transcribed to cDNA for 55 $\min$ at $42{ }^{\circ} \mathrm{C}$ using SuperScript ${ }^{\mathrm{TM}}$ Preamplification System for First Strand cDNA Synthesis (GIBICOL). Real-Time RT-PCR was performed using $\mathrm{ABI}$ StepOne Plus System $(\mathrm{ABI})$. The cycling protocol was listed as follows: $95^{\circ} \mathrm{C}$ for $5 \mathrm{~min}$, followed by 40 cycles of $95^{\circ} \mathrm{C}$ for $15 \mathrm{sec}, 63{ }^{\circ} \mathrm{C}$ for $20 \mathrm{sec}$, and $68{ }^{\circ} \mathrm{C}$ for $40 \mathrm{sec}$. After all amplification cycle, the melting curve was evaluated to ensure the specificity of PCR products. Each sample was treated in triplicate. The PCR products were detected using SYBR Green (QPK201, Toyobo, Japan). GAPDH gene was used as internal control. The sequences of the primers used were as follows:

c-kit: 5'-CTGGCTGCCAA ATCTCTGTGAA-3'; 5'AGATGACGAGCTGGCTCTGGA-3';

SCF: 5'-GGAGATGGCAGTTGTGACTA-3'; 5'CATGCTTTAAGGCCTTTGTCACGA-3'; 
PI3K: 5'-TGGGCACAGGGAAGACAA-3'; 5'ACCAGTTGGCTCGGCATA-3';

PKC: 5 -AAGTGAGAAACCCCGGCTAT-3'; 5'AGGCAAATCCCTTCCAGTCT-3';

GAPDH: 5'-TGATTCTACCCACGGCAAGTT-3'; 5'-TGATGGGTTTCCCATTGATGA-3'.

\section{Statistical analysis}

Data are presented as mean \pm SEM. Statistical analysis was performed with ANOVA followed by a Bonferroni's test using Prism software (Graphpad Software, CA, USA). Results at $p<0.05$ level were considered significant.

\section{RESULTS}

Feed intake and fecal excretion of loperamide-induced STC rats

Rats with STC had comparable feed intake with rats in the other groups. However, the Lop + ATL-III-treated groups showed less water consumption than the STC model group (Figure $1 \mathrm{~B}$ and $\mathrm{C}$ ). Moreover, the quantity and weight of stool, as well as their moisture content were decreased in STC model group, comparing with corresponding values in the normal control. However, ATL-III treatment reversed these changes (Figures $1 \mathrm{D}, \mathrm{E}$ and $\mathrm{F}$ ). These results show that ATL-III treatment (Figure $1 \mathrm{~A}$ ) did not alter feed intake, water consumption and fecal excretion of the STC rats.

\section{Effect of ATL-III on intestinal transit rate in loperamide-induced STC rats}

As shown in Figure $2 \mathrm{~A}$, the intestinal transit rate in STC model group was significantly lower when comparing to untreated control. The intestinal transit rates in STC model groups were recovered after ATL-III treatment in a dosedependent manner. Thus, ATL-III treatment improved intestinal transit rate in loperamideinduced STC rats.

\section{Effect of ATL-III on serum NOS, VIP, SS, and 5-HT of loperamide-induced STC rats}

The serum levels of NOS, VIP, SS, and 5-HT from loperamide-induced STC rats were assayed with ELISA. The levels of NOS, VIP, and SS were remarkably induced by loperamide, but downregulated by ATL-III treatment (Figures $2 \mathrm{~B}$, $D$, and $E$ ). In contrast, the level of 5-HT in STC model group was inhibited, while ATL-III treatment eliminated the inhibitory effect (Figure $2 \mathrm{C})$.
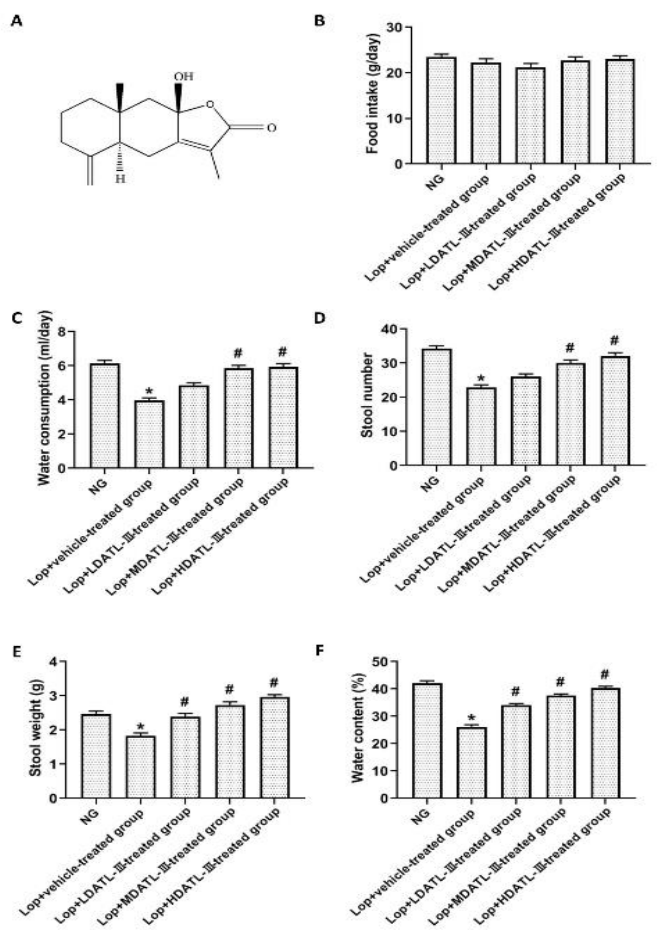

Figure 1: Effect of ATL-III on feed intake and fecal excretion in loperamide-induced STC rats; * $p<0.05$, Lop+vehicle-treated group was compared with normal control group (NG); \#p < 0.05, Lop+ATL-III-treated groups (three doses) were compared with Lop+vehicle-treated group

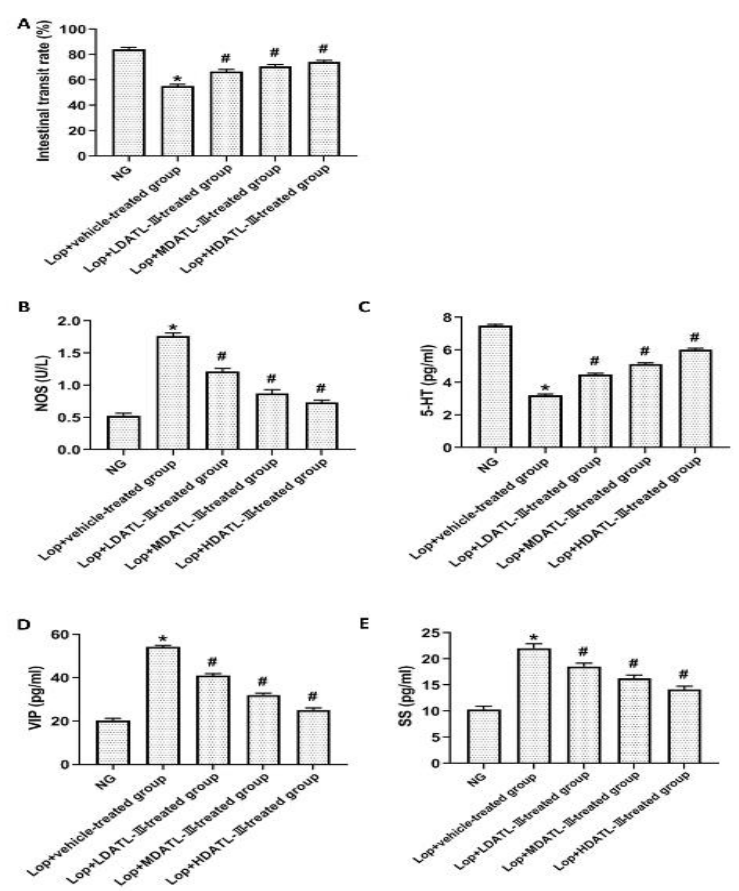

Figure 2: Effect of ATL-III on intestinal transit rate and neurotransmitter levels in blood in loperamide-induced STC rats. $\left({ }^{*} p<0.05\right.$, Lop+vehicle-treated group was compared with normal control group (NG); \#p $<0.05$, Lop+ATL-III-treated groups (three doses) were compared with Lop+vehicle-treated group) 


\section{Histological alterations in colon tissue}

To investigate the effect of ATL-III on structural alterations in colon tissue, smooth muscle cells, neuronal cells, and mucous layer were examined in rat transverse colons after $\mathrm{H}$ \& $\mathrm{E}$ staining (Figure 3 ). In the model group, the smooth muscle cells were atrophied and disorderly arranged; the neuronal cells of the colon tissue were reduced in population, and there was evidence of inflammatory cell infiltration in the mucosa. However, the colon smooth muscle cells and neuron cells of the rats in the Lop + ATL-III-treated groups appeared normal and similar to those of the control group, and the infiltration of inflammatory cells in the colon tissue was decreased.
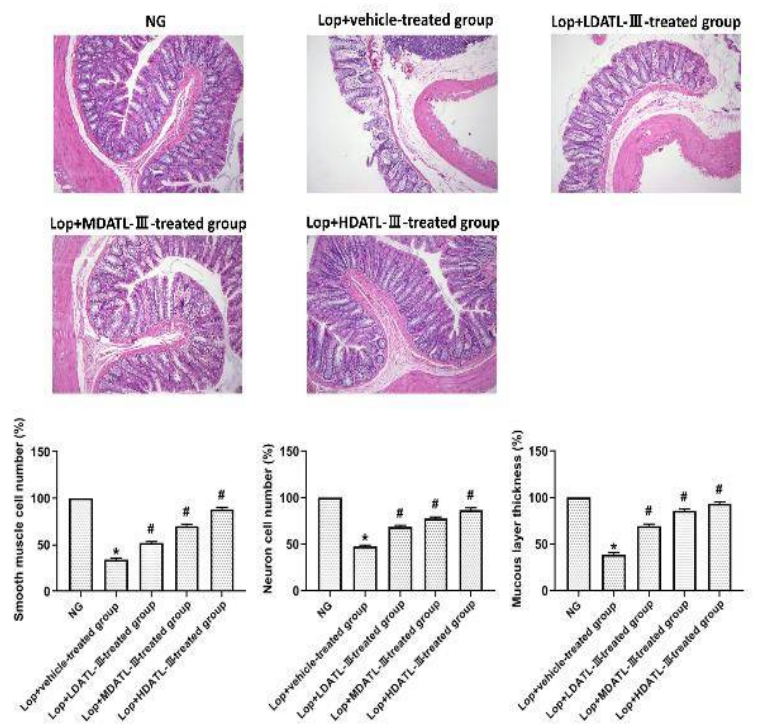

Figure 3: Effect of ATL-III on structural alterations of colon tissue in loperamide-induced STC rats. ${ }^{*} p<$ 0.05 , Lop+vehicle-treated group was compared with normal control group (NG); \#p < 0.05, Lop+ATL-IIItreated groups (three doses) were compared with Lop+vehicle-treated group

\section{Effect of ATL-III on expression of C-Kit, SCF, $\mathrm{PKC}$, and $\mathrm{PI}-3 \mathrm{~K}$}

As a specific marker of ICC, the immunoreactivity of C-kit was measured using immunohistochemistry. After staining with $D A B$, brown stained particles appeared in the cytoplasm. The expression of C-kit in colon tissue dramatically decreased to a basal level after loperamide treatment, and the distribution was sparse (Figure $4 \mathrm{~A}$ ). In contrast, the expressions of C-kit in colon tissues of Lop + ATL-III-treated groups were increased to various degrees, and the cells were densely distributed.

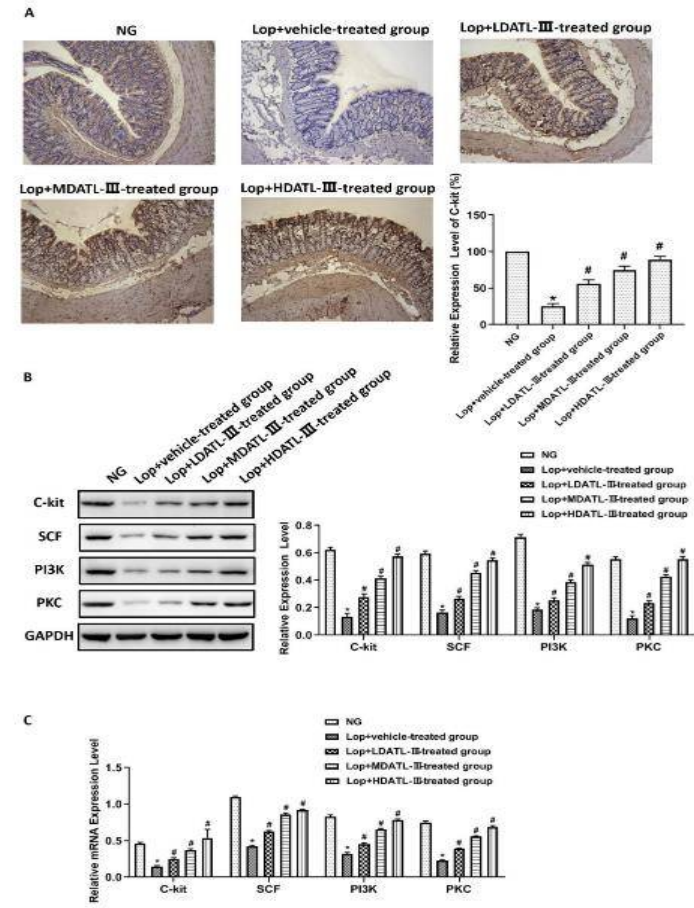

Figure 4: Effect of ATL-III on expression of C-kit, SCF, PKC, and PI-3K in the colon of Lop-induced STC rats. The immunoreactivity of c-kit was measured by immunohistochemistry, and expressions of c-Kit, SCF, $\mathrm{PKC}$, and $\mathrm{PI} 3 \mathrm{~K}$ of the colon tissue were measured by Western blot and real-time RT-PCR; ${ }^{*} p<0.05$, Lop+vehicle-treated group was compared with normal control group (NG); \#p < 0.05, Lop+ATL-III-treated groups (three doses) were compared with Lop+vehicle-treated group

The expressions of C-kit, SCF, PKC, and PI-3K were measured at both protein and mRNA levels, and the results are shown in Figure $4 \mathrm{~B}$ and $\mathrm{C}$. The expression of C-kit, SCF, PKC, and PI-3K at protein levels were remarkably lower after loperamide treatment. In addition, Lop + ATL-IIItreated groups had elevated c-kit, SCF, PKC, and PI-3K protein expression levels. Furthermore, the pattern of changes in mRNA expression levels was very similar to that of protein expression levels. Thus, ATL-III accelerated the transmission of electrical excitation and enhanced colon movement by increasing the expressions of c-kit, SCF, PKC, and $\mathrm{PI}-3 \mathrm{~K}$.

\section{DISCUSSION}

Slow transit constipation (STC) is due to various factors such as delayed colon movement and reduced fecal function. Surgical treatment does not fundamentally cure STC, and the side effects of drug treatment are enormous. The disease causes physical and mental agony to patients, while bringing them huge economic burdens. In recent years, Chinese medicinal herb and its 
extracts have been found to be effective in the treatment of STC, and they have attracted the attention of researchers. Atractylenolide-III (ATLIII) is a key active component of Atractylodes lancea. Therefore, the effect of ATL-III on loperamide-induced STC in rats was investigated in the present study. Feed intake, water consumption and fecal excretion are main factors when evaluating the severity of constipation and drug efficacy [14].

In this study, feed intake was not affected by ATL-III. In contrast, the amounts of feces and their moisture contents were decreased in the model group, while water consumption and urine volume were increased. However, these indices were gradually and dose-dependently improved by ATL-III to the levels of control group. Aloe ferox Mill. is widely used for its healing effects, and also effective in treating loperamide-induced constipation in rats, consistent with present study [15]. Furthermore, the intestinal transit rate was decreased in the model group, while it remained normal in low-dose, medium-dose, and highdose ATL-III groups. These results demonstrate that ATL-III treatment mitigates the changes in feed intake, water consumption, fecal excretion, and intestinal transit rate of loperamide-induced STC rats.

Intestinal motility is regulated by a complex neuroendocrine network composed of multiple neuropeptides, neurotransmitters and their receptors $[16,17]$. Neurotransmitters related to the pathogenesis of STC include nitric oxide (NO) [18], vasoactive intestinal peptide (VIP) [19], somatostatin (SS) [20], and serotonin (5HT) [21]. Abnormalities in the expressions of these neurotransmitters may be involved in the neuropathological mechanism of STC. Being the main suppressive transmitters of colonic motility, the concentrations of NO, VIP, and VIP in the colon tissue of ATL-III groups were understandably lower than those in the colonic tissue of the model group. Moreover, the excitable neurotransmitter 5-HT was increased in the ATL-III groups when compared with the STC model group, indicating that the inhibitory role of ATL-III on colonic movement was relatively weak.

The Cajal interstitial cells (ICC) are special cells that produce slow waves and regulate neurotransmitters and conduction of electrical excitability. They are located between gastrointestinal smooth muscle cells (SMC) and nerve cells, and are closely linked with gastrointestinal motility $[22,23]$. The specific marker of ICC is the proto-oncogene C-kit of the gastrointestinal tract, which is distributed on the surface of the cells [24]. After combining with its ligand stem cell factor (SCF), a chain reaction of intercellular signaling effectors is triggered by phosphorylation, resulting in the regulation of several signaling pathways, involving phosphatidylinositol-3 kinase (PI-3K) and other downstream substrates. The end-result is the activation of the cytosolic transcription factor which regulates gene expression and activation, and control cell proliferation, differentiation and growth $[25,26]$.

ENS is a complete intramural nerve system in the gastrointestinal tract that regulates the alimentary movement independently [27]. At present, it is generally believed that ENS, ICC and SMC form functional network connections. As a basic functional unit of gastrointestinal motility, this functional network effectively transmits nerve impulse to the SMC around them, resulting in gastrointestinal motility. The present study found that ICC, SMC, and nerve cells were significantly decreased in the model group, but were enhanced in the three ATL-III groups. The protein and mRNA expressions of C-kit, SCF, PKC, and PI-3K were increased in the ATL-III groups, when compared with model group, albeit at below-normal levels. Therefore, it may be suggested that ATL-III regulates the smooth muscle activity by elevating the number of ICCs, and SCF/c-kit exerts its effect through $\mathrm{PKC} / \mathrm{PI}-3 \mathrm{~K}$ pathway.

\section{CONCLUSION}

The results obtained in this study indicate that ATL-III exerts a significant enhancing effect on the colonic transit function of loperamide-induced STC rats, via a laxative mechanism involving enhancement of the expressions of SCF/c-kit and $\mathrm{PKC} / \mathrm{PI}-3 \mathrm{~K}$, and promoting the repair and regeneration of ICC. These effects result in recovery of intestinal motility and defecation ability. Thus, ATL-III has promising potential in the management and prevention of constipation.

\section{DECLARATIONS}

\section{Funding}

This work was supported by Research Project on Cadres Health Care of Jiangsu Province, China (Grant No. BJ16017); National Natural Science Foundation of China(Grant No.81804107); Jiangsu Hospital of TCM (Grant No. Y19059)

\section{Conflict of interest}

No conflict of interest is associated with this 
work.

\section{Contribution of authors}

We declare that this work was done by the author(s) named in this article and all liabilities pertaining to claims relating to the content of this article will be borne by the authors. All authors read and approved the manuscript for publication. Wang Hao and Gu Yunfei conceived and designed the study. Wang Hao, Gong Yuxia, $\mathrm{Li}$ Youran and $\mathrm{Xu}$ Minmin performed the experiments. Gu Yunfei carried out analysis of data. Gu Yunfei wrote the manuscript. All authors read and approved the manuscript for publication.

\section{Open Access}

This is an Open Access article that uses a funding model which does not charge readers or their institutions for access and distributed under the terms of the Creative Commons Attribution License (http://creativecommons.org/licenses/by/ 4.0) and the Budapest Open Access Initiative (http://www.budapestopenaccessinitiative.org/rea d), which permit unrestricted use, distribution, and reproduction in any medium, provided the original work is properly credited.

\section{REFERENCES}

1. Geijo Martínez F, Sánchez Garrido A, Marcos Prieto $H$, Piñeiro Pérez C, Prieto Bermejo AB, Álvarez Delgado A, Velasco Guardado A, Rodríguez Pérez A. Long-term results of linaclotide in the treatment of constipation-type irritable bowel syndrome. Rev Esp Enferm Dig 2018; 110(7): 451-457.

2. Ng KS, Montes-Adrian NA, Mahns DA, Gladman MA. Quantification and neurochemical coding of the myenteric plexus in humans: No regional variation between the distal colon and rectum. Neurogastroenterol Motil 2017; 30: 13193.

3. Binienda A, Storr M, Fichna J, Salaga M. Efficacy and safety of serotonin receptor ligands in the treatment of irritable bowel syndrome: a review. Curr Drug Targets 2018; 19: 1774-1781.

4. Cohen M, Cazals-Hatem D, Duboc H, Sabate JM, Msika $S$, Slove AL, Panis Y, Coffin B. Evaluation of interstitial cells of Cajal in patients with severe colonic inertia requiring surgery: a clinical-pathological study. Colorectal Dis 2016; 19(5): 462-467.

5. Wang JP, Ding GF, Wang QZ. Interstitial cells of Cajal mediate excitatory sympathetic neurotransmission in guinea pig prostate. Cell \& Tissue Res 2013; 352: 479486.

6. He DY, Dai SM. Anti-inflammatory and immunomodulatory effects of paeonia lactiflora pall, a traditional Chinese herbal medicine. Front Pharmacol 2011; 2: 10-16.

7. Li Z, Lin H, Gu L, Gao J, Tzeng C. Herba cistanche (Rou Cong-Rong): One of the best pharmaceutical gifts of traditional Chinese medicine. Front Pharmacol 2016; 7: 41-47.

8. Kang TH, Bang JY, Kim MH, Kang IC, Kim HM, Jeong HJ. Atractylenolide III, a sesquiterpenoid, induces apoptosis in human lung carcinoma A549 cells via mitochondria-mediated death pathway. Food \& Chem Toxicol 2011; 49(2): 514-519.

9. Liu C, Zhao $H$, Ji ZH, Yu $X Y$. Neuroprotection of atractylenolide III from atractylodis macrocephalae against glutamate-induced neuronal apoptosis via inhibiting caspase signaling pathway. Neurochem Res 2014; 39: 1753-1758.

10. Zhao H, Ji ZH, Liu C, Yu XY. Neuroprotection and mechanisms of atractylenolide III in preventing learning and memory impairment induced by chronic high-dose homocysteine administration in rats. Neurosci 2015; 290: 485-491.

11. World Health Organization. Principles of laboratory animal care. WHO Chron 1985; 39: 51-56.

12. Wang $R$, Wang $G$, Hao $H$, Xie $H$, Zhang J, Wu $F$. Quantitative determination of atractylenolide III in rat plasma by liquid chromatography electrospray ionization mass spectrometry. J Chromatogr B Analyt Technol Biomed Life Sci 2006; 831(2): 36-41.

13. Wang KT, Chen LG, Wu CH, Chang CC, Wang CC. Gastroprotective activity of atractylenolide III from atractylodes ovata on ethanol-induced gastric ulcer in vitro and in vivo. J Pharm \& Pharmacol 2010; 62: 381 388.

14. Moezi P, Salehi A, Molavi H, Poustchi H, Gandomkar A, Imanieh $M H$, Malekzadeh $R$. Prevalence of Chronic Constipation and lts Associated Factors in Pars Cohort Study: A Study of 9000 Adults in Southern Iran. Middle East J Dig Dis 2018; 10(2): 75-83.

15. Wintola OA, Sunmonu TO, Afolayan AJ. The effect of Aloe ferox Mill. in the treatment of loperamide-induced constipation in wistar rats. BMC Gastroenterol 2010; 10: 1-5.

16. Tillou J, Poylin V. Functional Disorders: Slow-Transit Constipation. Clin Colon Rectal Surg 2016; 30: 76-86.

17. Chen HB, Huang $Y$, Song HW, Li XL, He S, Xie JT, Huang C, Zhang SJ, Liu J, Zou Y. Clinical research on the relation between body mass index, motilin and slow transit constipation. Gastroenterol Res 2010; 3(1): 1924.

18. Tian $H$, Ge $X$, Nie $Y$, Yang $L$, Ding $C$, McFarland $L V$, Zhang $X$, Chen $Q$, Gong J, Li N. Fecal microbiota transplantation in patients with slow-transit constipation: A randomized, clinical trial. PLoS One 2017; 12(2): 171308.

19. Cheng L, Biancani PJ. Progesterone receptor A mediates VIP inhibition of contraction. Am J Physiol Gastrointest Liver Physiol 2010; 298: 433-439.

Trop J Pharm Res, June 2019; 18(6): 1203 
20. Chen W, Jiang CQ, Qian Q, Ding Z, Liu ZS. Antiperistaltic side-to-side ileorectal anastomosis is associated with a better short-term fecal continence and quality of life in slow transit constipation patients. Dig Surg 2015; 32: 367-372.

21. Tong $W$, Kamiyama $Y$, Ridolfi TJ, Zietlow A, Zheng J, Kosinski L, Ludwig K, Takahashi T. The role of 5-HT3 and $5-\mathrm{HT} 4$ receptors in the adaptive mechanism of colonic transit following the parasympathetic denervation in rats. J Surgical Res 2011; 171(2): 510516.

22. Knowles $\mathrm{CH}$, Farrugia G. Gastrointestinal neuromuscular pathology in chronic constipation. Best Pract Res Clin Gastroenterol 2011; 25: 43-57.

23. Beck K, Friebe A, Voussen B. Nitrergic signaling via interstitial cells of Cajal and smooth muscle cells influences circular smooth muscle contractility in murine colon. Neurogastroenterol Motil 2018; 30: 13300.
24. Cohen M, Cazals-Hatem D, Duboc H, Sabate JM, Msika $S$, Slove AL, Panis Y, Coffin B. Evaluation of interstitial cells of Cajal in patients with severe colonic inertia requiring surgery: a clinical-pathological study. Colorectal Dis 2016; 19(5): 462-467.

25. Beck $K$, Friebe A, Voussen B. Nitrergic signaling via interstitial cells of Cajal and smooth muscle cells influences circular smooth muscle contractility in murine colon. Neurogastroenterol Motil 2018; 30: 13300.

26. Tan $Y Y$, Ji ZL, Zhao G, Jiang JR, Wang D, Wang JM. Decreased SCF/c-kit signaling pathway contributes to loss of interstitial cells of Cajal in gallstone disease. Int $\mathrm{J}$ Clin Exp Med 2014; 7(11): 4099-4106.

27. Grosjean D, Benini $P$, Carayon P. Managing irritable bowel syndrome: The impact of micro-physiotherapy. J Complement Integr Med 2017; 14: 44. 